\title{
Technology for obtaining fodder additive for animals and birds
}

\author{
Gabdulahat Akhmadiev* \\ Kazan Federal University, 420008, 18 Kremlin st., Kazan, Russian Federation
}

\begin{abstract}
The purpose of this work is to analyze the existing problem and scientific and technical search for the development of an installation for the purpose of obtaining a feed additive. At the same time, we pay attention to the justification of the technology and application of the installation in order to obtain a feed additive for inclusion in the diet of various types of farm animals and birds. At the same time, the authors draw on the rationale and its use in order to obtain a feed additive for ensuring and further inclusion in the diet of various types of farm animals and birds. The set goal and tasks are solved by the proposed installation, designed to obtain a safe reserve feed additive from neutralized sludge sediments of treatment facilities, animal and poultry waste from the agro-industrial complex. The proposed innovative installation is designed to obtain a feed additive for various species of animals and birds. The developed technological algorithm with the installation produces safe, useful products. It can be used as a feed additive in the diet of farm animals and birds.
\end{abstract}

\section{Introduction}

The development of methodological foundations and principles, a model of digital technology of the problem, monitoring assessment, forecasting and improvement of the environment from wastes and emissions of the oil and gas industry, industrial transport, industrial construction and agro-industrial complex of urbanized agricultural fields and farms, industrial and abandoned non-industrial territories is an urgent state and the scientific and production unresolved target of Russia. Huge urbanized areas of the earth's surface occupied by agricultural land and industrial facilities are subject to pollution by various wastes, including industrial emissions, which have a significant impact on the ecological and economic state of animal husbandry, crop production of the agro-industrial complex and lead to a decrease in the quality of raw materials and finished products, both of animal and plant origin. In the aggregate, all these unfavorable factors and conditions are directly related to silt sediments, plant waste and animal waste. The designated environmental factors largely contribute to the reduction and suppression of acquired natural protection factors, internal structural and functional cellular resources, the body's resistance, or rather the natural resistance of farm animals, birds and plants. On the basis of unfavorable factors, there is a violation of the living conditions of living organisms and

\footnotetext{
*Corresponding author: ahmadievgm@mail.ru
} 
environmental safety conditions, the integrity of complex natural factors and planned natural nature-like, artificial industrial technologies for the reproduction of the planned herd, violation of the methods of ensuring environmental safety in the habitat of farm animals, birds, on the basis of high-quality, quantitative changes in crop yields. As a result, in combination, all of the above unfavorable factors lead to a decrease in the economic efficiency of crop production, animal husbandry, agriculture. At the same time, most of all, the agro-industrial complex is experiencing anthropogenic and technogenic pressure, including service personnel, animals and birds living in technogenic, altered urbanized agricultural areas. Taken together, they all cause significant environmental damage, removing fertile lands, which had good quality and quantity indicators, from agricultural circulation, thereby undermining the raw material base for livestock and poultry farming.

At present, most of all attention should be paid to the unsolved fundamental and applied ecological, medico-biological and technological problems of animal husbandry and veterinary sanitation, hygiene and ecology. It is known that in recent decades, all over the planet, including Russia, there have been global climatic changes, with abnormal warming, which lead to a sharp variability of weather conditions and their parameters throughout the seasons of the year and further contribute to a decrease or instability of precipitation in various regional territories Russia. As a result of a decrease in meteorological precipitation, there is a decrease in the efficiency and profitability of many agricultural sectors. One of the main factors supporting the stability of agriculture is the availability of grain reserves for crop, livestock and poultry farming, the availability of a fairly stable fodder base. With unstable environmental, climatic and weather conditions, difficulties arise in the management, organization, provision of technological and production processes of the agro-industrial complex, aimed at ensuring livestock and poultry farming with the necessary standard values, conditions for providing a sufficient volume of fodder [5]. Based on the above existing problems for the country's agricultural sector, an innovative technology for obtaining a feed additive from unused resources and reserves of the agroindustrial complex is required. This problem is urgent for peasant farms, agro-industrial firms, which also face similar natural, managerial, organizational, technological difficulties, now having factors and environmental conditions, unforeseen emergencies and natural, weather anomalous phenomena that impede the production, preservation, storage and providing livestock and poultry farming with a fodder base [6-11]. The purpose of this work is to analyze the existing problem, scientific and technical search for the developed devices, identify existing known analogues, select a prototype and develop an innovative technical solution with the installation of our modification for further obtaining a feed additive suitable for the morphological and functional characteristics of animals and birds.

\section{Methods}

The set goal and tasks are solved by the proposed innovative installation, designed to obtain a safe reserve feed additive from neutralized sludge sediments of treatment facilities, animal and poultry waste from the agro-industrial complex. The new technical solution is aimed at ensuring environmental, epidemiological, epizootic and raw material and food (feed) safety and ensuring the productive health and viability of the offspring of agricultural, domestic and wild animals of various species, plants and birds. Known installation for processing poultry droppings [12], containing a drying unit, the loading window of which by means of a feed conveyor communicates with the accumulator manure homogenizer, a device for grinding droppings, a cyclone installed at the outlet of the drying unit with a fan and a container for collecting dry droppings. The device for grinding manure is made in the form of a dispersing ejector, which is located at the outlet of the feeding conveyor, while the drying unit is made in the form of a pipe, a loading 
window, which is connected to the dispersing ejector [12]. The disadvantage [12] is the lack of a process for disinfecting poultry droppings or manure, when transported to the fields, and a safe technology for obtaining feed. This does not provide for the possibility of direct conversion of a part of manure and poultry manure into feed additives, while at least partial conversion is not always environmentally and energetically beneficial. Known installation for processing poultry droppings [13], including sequentially installed parts: a device for mechanical dehydration with a collector of distilled liquid, a dryer, a fluidized bed reactor, a cyclone, a condenser, a collection of liquid products of thermochemical decomposition of chicken droppings, as well as a device for unloading coal, a heat exchanger, a furnace, a device for preparing a drying agent, a device for saturating coal, and the collector of liquid products of thermochemical decomposition of chicken manure by means of a condenser through a cyclone is communicated with the fluidized bed reactor, and the furnace is connected through the annular space of the heat exchanger with a device for preparing a drying agent, a mechanical dehydration device - a collector of distilled liquid is connected by, sequentially located sterilizer and concentrator [13]. The disadvantage of the known technical solutions $[12,13]$ is the complexity of the design and the low degree of processing of poultry manure into organic fertilizer with a large amount of by-products (for example, coal) and the need to include unloading devices in the design of installations for these by-products of manure processing. A known method of waste disposal in a complex of waste-free poultry and animal husbandry with its own production of feed [14]. The method includes biotechnological and thermochemical processing of manure and dung to obtain electric and thermal energy, gaseous and liquid fuels. They are intended for use both in the processing of manure and dung, and for the preparation of feed, feed additives used to obtain livestock and poultry products, organic and inorganic fertilizers for the cultivation of forage crops in the production of feed. The disadvantage of the proposed method of waste disposal in the complex of waste-free poultry and animal husbandry with its own production of feed [14] is the lack of integrated information sensors that control the flow of the technological cycle and the final qualitative and quantitative characteristics of the products. The known method, implemented in a complex for wastefree poultry and pig breeding with its own production of feed and energy [15]. According to the conditions of the proposed method, manure and droppings formed during the life of farm animals and poultry are subjected to biotechnological and thermochemical processing by breeding dung worms, anaerobic digestion in a digester and aerobic digestion in manure trenches, thermochemical processing is implemented through pyrolysis and drying of manure, dung. As a result of such processing, electric and thermal energy, gaseous and liquid fuels, feed additives, organic and inorganic fertilizers are generated. Feed additives are directly used to obtain livestock and poultry products, organic and inorganic fertilizers are sent to the cultivation of forage crops, while gaseous and liquid fuels are used as a motor fuel. Thermal and electrical energy is used directly for the production of livestock and poultry products, biotechnological and thermochemical processing of manure and dung and feed preparation. These technological processes are united by a single automatic control system, which provides "the ability to intervene" in the technological process immediately by automatically receiving information about the undesirable mode. The proposed well-known technical solution [15] is laborious, with economically unprofitable costs, and the technological cycle is not controlled by recording sensors for the content of harmful chemical and beneficial nutrient organic and inorganic substances. It is not aimed at obtaining a universal (reserve) feed for different species of animals and birds, by granulating the dried mixture into food, feed granules, in addition, it does not determine the qualitative and quantitative indicators of nutritional value and energy value, both organic and inorganic minerals included in the composition of feed pellets. The closest to the claimed technical solution [16], the prototype, is an installation for disinfection, disposal 
and production of universal pelleted feed from agricultural waste. The installation provides a gas generator, a centrifuge separator for cleaning combustible gas from aerosol harmful suspended substances, a bactericidal ultraviolet lamp, a device for stirring sludge with sawdust and fallen leaves in a 1: 1 ratio, and a device for drying a mixture of sludge, sawdust and fallen leaves, a screw-press for granulating the dried mixture into briquettes, sensors for monitoring temperature, humidity, pressure, determining the volume of briquettes and ash [16]. The disadvantage of the prototype [5] is that the known technical solution did not provide for absorbers-traps in technological units that control the presence of chemical, man-made pollutants, medicinal substances, paints and other harmful substances and react to them at the initial stage, which can provide the technology environmental safety in the production of reserve food or feed products. At the same time, the ultimate goal is not considered to increase the environmental efficiency of the installation for processing waste from the agro-industrial complex into safe food (feed) products. At the same time, indicator sensors that react to the presence of harmful generated chemicals, an absorber filter (trap) for cleaning from foreign pollutants, dispensers for regulating the missing macro and micronutrients that make up safe feed products are not provided.

\section{Results}

The installation is a single constructive digital technical system and has sequentially located sections, functionally connected technological units. The installation includes a gas generator, a centrifuge for cleaning combustible gas, a bactericidal ultraviolet lamp and a device for mixing sludge with sawdust and fallen leaves in a 1: 1 ratio [4]. At the same time, a screw press is adapted and attached to the device for drying a mixture of sludge, sawdust and fallen leaves, as a technological target constructive - functional element for granulating a dried complex mixture into feed briquettes, digital information sensors for monitoring temperature, humidity, pressure and volume determination briquettes and ash. The installation is additionally equipped with a conveyor, a working tank, a sterilizer and a separator for cleaning combustible gas from aerosol suspended substances. The device for mixing manure with crop waste is equipped with a temperature regulator for drying and maintaining the temperature within 100 -120 degrees Celsius and a pressure sensor, which have a direct effect on the mixture of manure (droppings) with plant residues and according to the technical rules provided for the technological cycle passing into the auger - press for granulating the dried disinfected mixture. An innovative feature of this development is that information digital sensors are attached to the installation for the initial and final control of the presence of harmful substances, the content of organic and inorganic substances and the actual humidity, temperature, pressure and volume of foreign mechanical and chemical impurities that make up the feed pellets. The installation additionally includes a conveyor, a container, a separator, a sterilizer for disinfecting manure with added crop waste.

\section{Discussion}

The innovative basis of digital technology for obtaining a feed additive for animals and birds is the use of sawdust or fallen leaves, depending on the weather, climatic conditions of the animals and the time and season of the year. The technology for producing granulated food and feed additives is based on an innovative nature-like algorithm for processing waste from livestock, poultry and crop production with a reliable safe installation, based on the created technical and technological units, installation parameters based on lower threshold values of low-temperature pyrolysis. The installation provides for 
the intended purpose and use of a pasteurizer and a sterilizer-autoclave, depending on the season of the year, technological conditions in accordance with the set goal and objectives. In the installation, the determining factor is the temperature of the technological process, and the electronic sensor in the device maintains the required temperature, in the range from 70 to 120 degrees Celsius [5].

\section{Conclusion}

Thus, the proposed innovative installation is designed to obtain a feed additive for various species of animals and birds. The set goal and tasks are solved with the help of an installation aimed at a technical and technological solution in order to obtain safe, useful products from agricultural waste. The technology of processing and obtaining safe useful products from agricultural waste is based on low temperature pyrolysis. Low temperature pyrolysis is carried out at a plant for the disinfection and disposal of animal, poultry and crop waste. As a model, we use an installation of our constructive functional modification, intended purpose and based on the use of low temperature technological parameters of pyrolysis. The installation includes a pasteurizer and an autoclave sterilizer for innovative digital technology for processing agricultural waste into useful safe products. In the proposed installation, a significant and decisive factor is the temperature of the technological process, maintained by the sensor, in the range from 70 to 120 degrees Celsius. The developed technological algorithm with the installation of our modification can make it possible to obtain safe, useful products. The resulting feed products can be used as a feed additive for inclusion in the diet of farm animals and poultry. At the same time, the feed additive can be used in specially protected natural areas, reserves, national parks and reserves for various wild species of animals and birds, especially in unfavorable climatic and weather conditions of the season. The proposed installation can be useful, especially when there is a shortage of feed in order to ensure a positive balance and adequate feeding of animals and birds, in particular with the addition of a reserve feed additive, especially when there is a deficiency in their diet of basic nutrients, organic and inorganic substances.

\section{References}

1. F.F. Alekseev, M.A. Asriyan, Industrial poultry farming (Moscow, Agropromizdat, 1991)

2. D.A. Kovalev, E.N. Kamaydanov, RF patent RU № 2519853, IPC A01K 29/00, C05F 11/00 (2014)

3. A.V. Dubrovin, I.I. Sventitsky, A.V. Golubev, RF patent RU № 2423826, IPC A01K 29/00, C05F 3/00 (2011)

4. G.M. Akhmadiev, R.S. Akhmetshin, Patent for a useful model of the Russian Federation RU № 172829, IPC C02F 11/10, C02F 11/12, F23G 7/00 (2017)

5. G.M. Akhmadiev, G.V. Mavrin, M.N. Miftakhov, R.N. Sharafutdinov, N.N. Smirnova, Patent for invention RU № 2709324, MPKA23K10 (2019)

6. T. Morozova, S. Semyonov, Key Engineering Materials, 683 (2016)

7. T.S. Morozova, S.Y. Semyonov, A.K. Sibataev, The European Proceeding of Social \& Behavioral Science EpSBS (2017)

8. T. Morozova, S. Semyonov, AIP Conference Proceedings (2017)

9. T.S. Morozova, S.Y. Semyonov, Principles of Ecology, 2 (2017) 
10. I.F. Gorlov, M.I. Slozhenkina, D.V. Nikolaev, Y.D. Grebennikova, Kh.B. Garyaeva, Research journal of pharmaceutical biological and chemical sciences, 2 (2019)

11. I.F. Gorlov, M.I. Slozhenkina, A.V. Randelin, D.V. Nikolaev, Yu.D. Grebennikova, Kh.B. Garyaeva, D.A. Mosolova, Research journal of pharmaceutical biological and chemical sciences, 2 (2019)

12. U. Baresia, K. J. Vellab, N. G. Sipea, Environmental Impact Assessment Review, 62 (2017)

13. F. Retiefa, A. Bondb, J. Poped, A. Morrison-Saunderse, N. Kingf, Environmental Impact Assessment Review, 61 (2016)

14. U. Jha-Thakur, T. B. Fischer, Environmental Impact Assessment Review, 61 (2016)

15. M. Kågström, Environmental Impact Assessment Review, 60 (2016)

16. T. Perminovaa, N. Sirinaa, B. Larattea, N. Baranovskayab, L. Rikhvanov, Environmental Impact Assessment Review, 60 (2016) 